\title{
Population Ageing in Eastern Europe: Toward a Coupled Micro-Macro Framework
}

László J. Kulcsár Population ageing has been a major demographic

Department of Agricultural

Economics, Sociology, and

Education

The Pennsylvania

State University

E-mail:1zk68@psu.edu

David L. Brown

Cornell University

Department of Development

Sociology

E-mail: dlb17@cornell.edu

Keywords:

ageing,

Eastern Europe, community capacity, rural, demography trend in Europe. The post-socialist countries are still younger than the European average, but their age transitions are well underway. These transitions are particularly challenging in the rural areas of the region. These areas often do not have enough resources or sufficient community capacity to address the challenges of ageing in place. Although there is considerable variation in the way that ageing influences rural municipalities, it is important to consider an overall framework to investigate this variation. This paper presents an interlinked approach that aims to connect the macrolevel and micro-level perspectives on population ageing through the example of Eastern Europe and a detailed study of Bulgaria and Lithuania. Using the unique challenges faced by rural communities in post-socialist countries, we propose a framework for such research in Eastern Europe.

\section{Introduction}

Population change is inextricably linked with other aspects of social and economic development at the national, regional, and local levels. Changes in population size generally attract the most attention, but changes in population structure, particularly age structure, are important (Brown-Eloundou-Enyegue 2017). Population changes influence, and are influenced by, macro-level factors, such as economic transformations, regime transitions in governance, and entry into multi-national political and economic arrangements. There is virtually no aspect of a country's social and economic structure not linked to at least one demographic trend.

The process of modernization and capitalist development during the $20^{\text {th }}$ century is associated with numerous well-known demographic processes, among which global declining birth rates is one of the most significant. Accompanying this trend, life expectancy at birth has increased in many countries because chronic diseases have replaced contagious diseases as the major causes of mortality and advancements in public health have reduced infant mortality rates. Increased life expectancy

Regional Statistics, Vol. 7. No.1. 2017: 115-134; DOI: 10.15196/RS07107 
is usually considered a positive indicator of socioeconomic development; however, the corresponding ageing of populations has often evoked alarmist commentaries because countries struggle with the challenges of providing care and support of their increasing numbers of retired workers, who are comprising growing shares of total populations (Brown-Eloundou-Enyegue 2017). Ironically, only a few decades after the alarmist concerns about apparent uncontrollable population growth (Ehrlich 1968), ageing, not "overpopulation," was tagged as the next global demographic challenge, particularly in countries with large post-World War II birth cohorts entering retirement age (Kinsella-Phillips 2005, Pool 2005).

According to the latest revision of World Population Prospects, about 12 per cent of the world's population, accounting for more than 900 million people, were aged 60 or older in 2015. This number is projected to reach 1.4 billion, or $16.5 \%$ of all people, by 2030 (UN, 2015). This is the fastest growing segment of the global population, although regional dynamics show considerable variation. For example, European countries are ageing more rapidly than other regions, mainly due to persistently low fertility. Europe's median age in 2015 was about 42 years, which the global population is not projected to reach until 2100 (UN 2015).

In Europe, the former socialist countries of the Eastern periphery have experienced rapid population ageing along with the rest of the continent. By 2000, fertility had fallen below replacement in all of the former socialist nations, except Albania and the Muslim-majority successor states of the Soviet Union. In addition, many of these countries lost young adults to labour emigration. The combination of these two trends radically changed Eastern Europe's age structures within two generations. However, one aspect changed only moderately, namely, lower life expectancy at birth and, particularly, at older ages, persisted in Eastern Europe compared to the West. Although it remains younger than the rest of Europe, Eastern Europe has significantly aged.

A demographic analysis of global or regional ageing could provide valuable background for public policymaking at the national or regional level by providing the necessary historical context for understanding and projecting long-term socioeconomic changes. However, because demographic change is mediated by variation in social structures, demography can only take scholarly inquiry on the implications of population ageing so far. Because population dynamics have considerable social and economic inertia, their actual influences might be overlooked.

This study focused on the effects of population ageing on communities as a specific framework for demographic analysis. Demographic scholarship during recent decades has moved towards combining contextual and historical knowledge with qualitative and quantitative case studies (Thiede et al. 2017). This is an important development because the policy tools at the national level, where most of the data are collected and analysed, might not suitably address community-level situations.

Regional Statistics, Vol. 7. No.1. 2017: 115-134; DOI: 10.15196/RS07107 
Concurrently, developed locality-specific solutions to problems might not be accessible by other communities struggling with similar challenges.

The link between macro-level (national or large regional) and micro-level (community) fits the broad approach of incorporating history and culture into demography. This is a challenging process given the inherently quantitative nature of population studies and the qualitative (including ethnographic) traditions of scholarship on history, culture, and micro-level social organization (Bachrach 2014). It would be relatively easy to incorporate contextualized or community studies in this process (which is one way to understand micro-perspectives), but we suggest linking the macro-level to the micro-level analysis, which begins with the individual as the unit of analysis.

This study employs an interlinked approach that aims to connect the macro-level and micro-level perspectives on population ageing using the example of Eastern Europe. We start by discussing the long-term ageing trends of the post-socialist region, and, then, we explore the special case of rural ageing. We focus on rural areas because they often have the fewest resources with which to address these challenges. Although there is significant variation among rural areas, even to the extent that the urban and rural dichotomy is under increasing scholarly scrutiny (Brown-Shucksmith 2017f), rural communities share many similarities. Thus, demographic trends, such as population ageing, might create similar challenges for rural communities around the world, and international comparative work on these topics potentially identifies solutions and ideas otherwise unavailable to the relevant stakeholders. This line of research builds on the two basic themes proposed by Glasgow and Berry (2013) in their seminal study on rural ageing: (1) what makes ageing different in rural areas compared to urban areas and (2) how does ageing change the nature of rural places. Our study examines these themes in the context of Eastern Europe.

\section{Ageing in Eastern Europe}

Population ageing is largely a function of declining birth rates. Improving life expectancy is also a factor, but contrary to the intuitive opinion, increasing proportions of older adults (those aged 65 or older) are not driven simply by more people surviving to and during old age. A third basic component of population change is migration, which can play a crucial part in ageing, depending on its age selectivity. Because migration is generally selective of younger cohorts, negative net migration removes younger persons from a population. Exacerbating the problem, this is the age group with the highest reproductive capacity; therefore, losing young adults through emigration doubles the impact on population ageing because they take their children and future reproductive potential with them.

Regional Statistics, Vol. 7. No.1. 2017: 115-134; DOI: 10.15196/RS07107 
As stated above, ageing in Europe is considered a major challenge, which has energized many scholars and policymakers to address its issues and potential solutions. In a recent report, the European Commission took a broad and standard approach to pensions, the labour market, and the human capital implications of population ageing (EC 2014). Interestingly, the challenges to rural areas were not among the identified problems, although copious research has identified rural ageing as a particular challenge (see the special issue of Journal of Rural Studies focusing on rural ageing, (i.e., Milbourne 2012). In fact, the word "rural" is not even mentioned in the 76-page report.

Population ageing in Eastern Europe also has been a focus of academic discourse for some time. The aptly named World Bank report 'From Red to Grey' argued a decade ago that the age transition in the post-socialist countries will be faster and exert a stronger impact than in Western Europe (World Bank 2007). The somewhat optimistic position of the report was that the effects of ageing could partially be offset by increasing the labour force participation rates of the existing workforce, which works if that potential is not eroded by large-scale outmigration.

Outmigration, already a serious problem for several post-socialist countries, contributes to overall population decline as well as population ageing. Of the 27 countries in the afore-mentioned World Bank report, 20 were projected to lose population in the near future. In the geographic periphery of Europe, only Albania and Macedonia are expected to grow; the other former socialist countries with projected population increases are in Central Asia. For several countries, such as Hungary, Bulgaria, and Romania, combined ageing and population loss has been a familiar trend since the 1980s. For example, in Bulgaria, 30 years of population growth was lost in just the first ten years after its political transition, and some observers have characterized the country's current demographic trend as a 'national catastrophe' (Vassilev 2005). Thus, in contrast to countries in the global north, post-socialist nations are not only becoming older; the trend is occurring simultaneously with a dramatically shrinking population base. Smaller sizes and older populations are framed as a 'social problem' associated with insufficient labour to maintain economic growth and with rising age dependency and its associated increases in social welfare.

As shown in Table 1, Europe's median age increased from 28.9 to 41.7 between 1950 and 2015 (UN 2015). The corresponding change in Eastern Europe was from 25.9 to 39.6. Eastern Europe is slightly younger, but the gap between it and the continental average has shrunk from three to two years, indicating that the postsocialist periphery is ageing faster than its Western counterpart. It is projected that the difference by 2040 will be just one year.

Regional Statistics, Vol. 7. No.1. 2017: 115-134; DOI: 10.15196/RS07107 
Table 1

Aging in Eastern Europe in the European context ${ }^{1}$

\begin{tabular}{l|c|c|c|c}
\hline \multirow{2}{*}{} & \multicolumn{2}{|c|}{ Median age } & \multicolumn{2}{c}{ Percent 65+ } \\
\cline { 2 - 5 } & Europe & Eastern Europe & Europe & Eastern Europe \\
\hline 1950 & 28.9 & 25.9 & 8.0 & 5.9 \\
1960 & 30.3 & 28.0 & 8.8 & 6.6 \\
1970 & 31.7 & 30.9 & 10.5 & 8.5 \\
1980 & 32.6 & 31.5 & 12.4 & 10.8 \\
1990 & 34.7 & 33.6 & 12.7 & 10.8 \\
2000 & 37.7 & 36.6 & 14.7 & 12.9 \\
2010 & 40.4 & 38.6 & 16.4 & 14.1 \\
$\mathbf{2 0 1 5}$ & 41.7 & 39.6 & 17.6 & 14.7 \\
2020 & 42.7 & 40.8 & 19.3 & 16.7 \\
2030 & 45.1 & 43.8 & 23.1 & 20.1 \\
2040 & 46.7 & 45.8 & 25.7 & 21.4 \\
\end{tabular}

Source: UN: World Population Prospects: The 2015 Revision.

However, the proportions of the 65 or older $(65+)$ segments present the opposite trend. In 1950, the difference was about $2 \%$ in favour of Eastern Europe. By 2015, the difference had grown to 3\%. In other words, whereas the change in median age means that Eastern Europe is catching up to the continental average, in terms of the growth of the $65+$ segment of the population, a convergence has not materialized. One reason for this seeming inconsistency is that, although the shape of the population pyramid (age structure) is becoming 'rectangular' in Western and Eastern Europe, life expectancy in Eastern Europe lags behind the European average, meaning that many people do not live long enough to enter the 65+ age group. On average, European men and women currently live to 73 and 81 years, respectively (UN 2015). The corresponding life expectancies of Eastern European men and women are 67 and 77 years, respectively. The gap between the two geographic regions is larger regarding life expectancy at age 65. In contrast, the convergence in median age is caused by a declining youth and young adult share of the population because of chronically low fertility across Europe and the net outmigration of workers in Eastern Europe.

These changes mean that single indicators might not provide accurate assessments of population ageing for the region. The interaction of various demographic trends is the force that produces the outcomes and challenges, and, in Eastern Europe's case, ageing has been influenced by morbidity and mortality more than antic-

\footnotetext{
1 This designation of Eastern Europe follows the United Nations classification, and includes the following countries: Belarus, Bulgaria, Czech Republic, Hungary, Poland, Republic of Moldova, Romania, Russia, Slovakia, and Ukraine.
}

Regional Statistics, Vol. 7. No.1. 2017: 115-134; DOI: 10.15196/RS07107 
ipated. The Eastern European mortality crisis, which is inadvertently maintaining a younger population, has been well documented (Compton 1985, Meslé 2004, Cunningham 2009). It stems from the failure of healthcare systems to provide the institutional capacity necessary to treat chronic diseases following the epidemiological transition. This failure is coupled with culturally specific public health behaviours, such as a high prevalence of smoking, excessive alcohol consumption, and low levels of physical exercise, particularly among males. It has been pointed out that the mortality pattern creates difficulties for projecting the sizes and compositions of these countries' 65+ populations (Gavrilova-Gavrilov 2009).

Figure 1

Percent 65+ in Eastern Europe and its subregions

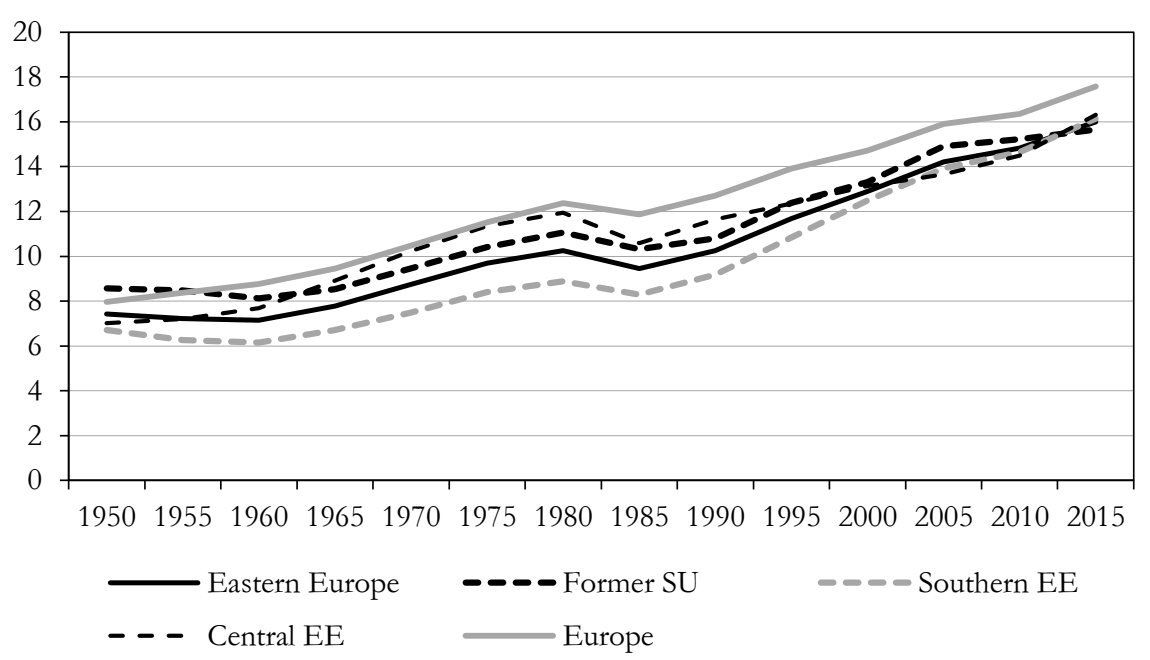

Source: UN: World Population Prospects: The 2015 Revision.

Figure 1 shows the per cent of the 65+ populations of Europe, Eastern Europe as a region (20 countries), and three unique sub-regions. ${ }^{2}$ Ageing increased until the mid-1970s, when the echo of the post-war baby boom temporarily changed the age composition. However, this change was temporary, and, by the 1990s, the shares of the $65+$ segments were rapidly increasing again. This happened because of declining fertility caused by the uncertainty of the post-communist political and economic changes that were hitting the region at an unfortunately crucial time due to cohort dynamics. The echo boomers, born in the 1970s, faced adverse economic conditions during their traditional years of family formation, which lowered their completed fertility below the expected rate. Furthermore, they were disproportionately among

2 The three sub-regions are the former Soviet Union (Belarus, Estonia, Lithuania, Latvia, Moldova, Russia, and Ukraine), the southern countries (Romania, Bulgaria, Serbia, Croatia, Slovenia, Bosnia-Herzegovina, Macedonia, Montenegro, and Albania), and Central Europe (Poland, Czech Republic, Hungary, and Slovakia).

Regional Statistics, Vol. 7. No.1. 2017: 115-134; DOI: 10.15196/RS07107 
those who emigrated. Therefore, by 2015 , the shares of the $65+$ segments of the populations of most of those countries had reached about 16\%. Figure 1 also shows a conversion effect, which indicates that the historical differences among the former socialist countries have slowly been disappearing. However, in every year, the three Eastern European sub-regions had lower $65+$ proportions than the continental average. Hence, although Eastern Europe has aged with the rest of the global North, it still lags behind the rest of Europe, at least with respect to conventional measures, such as median age and the proportional share of the $65+$ segment of the population.

The data in Figure 2 show the differences in the proportions of the 65+ segments of the populations among the EU and Eastern Europe's three distinct subregions. The average of the 20 countries (labelled 'EE-EU difference') indicates that ageing in Eastern Europe was slower than the continental average until about 1990, when the gap began to close, and this convergence is observed throughout the post1990 period. However, the reason for this convergence differed across Eastern Europe. High fertility and lower life expectancy kept the former Soviet Union and the Southern European countries younger relative to the age progression in the EU. In Central Europe, rapidly declining fertility (partly due to easily available induced abortions) kept the proportions of the $65+$ segments closer to the continental average until the 1970s, when the echo of the baby boom caused the age composition to be younger. By 2015, the sub-regional differences in Eastern Europe had disappeared; however, previous inter-regional differences will influence these populations into the future.

Figure 2

Difference in the percent $65+$ population between Europe and Eastern Europe

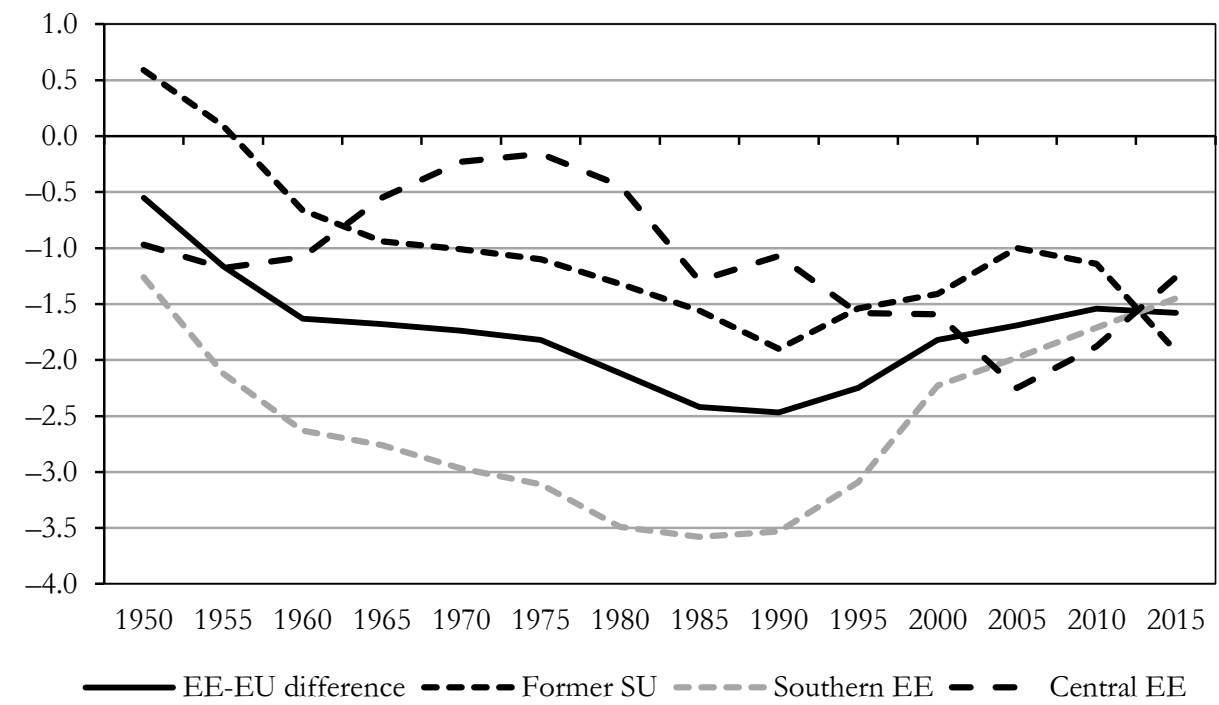

Source: UN: World Population Prospects: The 2015 Revision.

Regional Statistics, Vol. 7. No.1. 2017: 115-134; DOI: 10.15196/RS07107 
A relatively young population is not necessarily indicative of fewer populationrelated challenges at the local level. Because the Eastern European mortality patterns stem from detrimental lifestyle-related health behaviours, the quality of life after retirement must also be considered. It is obvious that older adults in the region typically have relatively more difficulties, which is a problem for public policy to address. However, aggregating individual experiences at the community level also means that places with higher than average proportions of older adults must provide more extensive healthcare and social services to their less healthy populations at the same time when their workforce is shrinking. Rural communities in Eastern Europe are prime examples of the problem of increasing dependency.

\section{Ageing in rural areas}

It is well established that the proportional increase of older adults in a population creates a labour shortage when other demographic and economic conditions, such as migration, labour force participation, and enhanced labour productivity, are unchanged. In the absence of specific policies, such as large-scale immigration or guest worker programs and initiatives to either intensify production with technological advancements or to keep older adults in the workforce, economic production at the national level is jeopardized.

This challenge is exacerbated at small geographical scales, particularly in rural areas. In most cases, the issue is triggered before the age transition is apparent at the national level. This process is remarkably similar between rural areas in Western and ex-socialist countries. The development of urban industries and amenities has had the same impact on rural areas on both sides of the Iron Curtain. Population displacement, whether through the mechanization or the collectivization of agriculture, has created a large-scale rural to urban migration flow. Once traditionally high rural birth rates have declined, these areas no longer can counterbalance migration loss, and rural communities start to experience population decline and ageing in place. This typically occurred in the 1970s, although the fertility echo of the post-war baby boom kept it hidden for some time. In addition, governments and international organizations were focusing on the problems of rapid urbanization and the services and housing deficiencies of cities (Timberlake-Kentor 1983), hardly considering rural areas more than as labour reserve pools. However, by the 1980s, rural depopulation and ageing were occurring around the globe.

The 2015 EU Demographic Report indicated that, between 2004 and 2014, the proportion of the $65+$ segments increased by $4 \%$ in the European Union, reaching 18.5\% (European Union 2015). A cursory look at the report confirms our argument of the previous section that Eastern Europe is still slightly younger than the EU average. However, reliable data for vertical (urban-rural) and horizontal (across regions/countries) classifications are difficult to obtain, making detailed comparisons

Regional Statistics, Vol. 7. No.1. 2017: 115-134; DOI: 10.15196/RS07107 
impossible for most European countries. Most EU reporting uses the NUTS-3 level to aggregate population dynamics below the national level. However, this level is largely useless for urban-rural comparisons. In addition, rurality is based on the OECD typology of predominantly rural, intermediate, and predominantly urban categories. This typology is based on the percentage of the population living in rural communities, except when an area includes an urban core of a certain size, which automatically categorizes the entire region as non-rural.

The latest available report using this general typology across the member states was published in 2010 (Goll 2010). It used change in population composition, including the $65+$ segment of the population, by country and employed the tripartite rural typology. Although based on data reported at the NUTS-3 level, it allowed for some general observations about rural-urban population dynamics. In the EU-27, growth of the $65+$ segment of the population between 2001 and 2006 was exactly 1\%. This rate was the same in the predominantly urban and the predominantly rural regions, although rural regions had a slightly (0.3\%) higher proportion of older adults in 2001. Focusing on the former socialist countries, it is clear that these countries cannot be treated as an undifferentiated demographic region and generalized (Table 2).

Table 2

Percent of $65+$ population in predominantly rural and urban regions in selected Eastern European countries

\begin{tabular}{l|l|r|r|r}
\hline \multicolumn{1}{c|}{ Country } & \multicolumn{1}{|c|}{ NUTS-3 region } & 2001 & 2006 & Change \\
\hline EU-27 & Predominantly rural & 16.2 & 17.2 & 1.0 \\
Bulgaria & Predominantly urban & 15.8 & 16.9 & 1.1 \\
& Predominantly rural & 17.9 & 19.1 & 1.2 \\
Czech Republic & Predominantly urban & 14.6 & 14.8 & 0.2 \\
& Predominantly rural & 13.8 & 14.4 & 0.6 \\
Estonia & Predominantly urban & 16.3 & 15.6 & -0.7 \\
& Predominantly rural & 15.5 & 16.4 & 0.9 \\
Latvia & Predominantly urban & 16.0 & 18.2 & 2.2 \\
& Predominantly rural & 16.0 & 16.9 & 0.9 \\
Hungary & Predominantly urban & 12.9 & 14.2 & 1.3 \\
& Predominantly rural & 15.1 & 15.9 & 0.8 \\
Poland & Predominantly urban & 17.8 & 18.1 & 0.3 \\
& Predominantly rural & 11.8 & 12.5 & 0.7 \\
Romania & Predominantly urban & 13.4 & 14.9 & 1.5 \\
\multirow{3}{*}{ Slovakia } & Predominantly rural & 14.2 & 15.5 & 1.3 \\
& Predominantly urban & 13.8 & 14.5 & 0.7 \\
& Predominantly rural & 12.3 & 12.7 & 0.4 \\
& Predominantly urban & 12.0 & 12.2 & 0.2
\end{tabular}

Source: Goll 2010.

Regional Statistics, Vol. 7. No.1. 2017: 115-134; DOI: 10.15196/RS07107 
In the Czech Republic, Estonia, Hungary, Poland, and Estonia, the proportion of the $65+$ segment of the population was larger in urban than in rural regions in 2001 and in 2006. On the other hand, Bulgaria, Romania, Latvia, and Slovakia had proportionally larger elderly populations in rural areas. This heterogeneity suggests that some national and sub-national trends have significant roles along the urbanrural continuum for causing age composition outcomes.

To explore these differences more deeply, we selected two countries, Lithuania and Bulgaria, for further analysis. We aimed to compare countries that are culturally and historically different and located in different sub-regions of Eastern Europe. Another consideration was that both countries experienced significant population loss during the study period that exacerbated the age transition at the national levels, thus making rural-urban differences more obvious. Data were obtained from the Official Statistics Portal of Lithuania (http://osp.stat.gov.lt/en/home) and the National Statistical Institute's website in Bulgaria (http://www.nsi.bg/en).

We selected two data points, 2002 and 2015, for the analysis. Five-year age groups were created for both years, separately for urban and rural areas. The urban and rural designations followed the official statistical typologies of the respective countries. No attempt was made to harmonize those designations with each other or with a typology developed by the OECD or the EU. We considered 'rural' a socially constructed category, and we took the position that each country has a unique understanding and designation of 'rural' and that their designations are more valid than an administratively generated unified typology.

To compare change between the two points in the two countries, we standardized the age composition in four analytical categories in 2002 and 2015 (Lithuanian rural, Lithuanian urban, Bulgarian rural, Bulgarian urban), creating eight analytical categories. In other words, age distribution in rural Bulgaria in 2002 used the base of all rural Bulgarian residents in 2002, and so on.

The data in Figure 3 show the standardized age composition differences between the urban and rural areas of Lithuania for 2002 and 2015. Where the line is above zero, there is a higher proportion of rural population in the given age category, and, where the line is below zero, there is a higher proportion of urbanites. Again, these figures are relative to the total rural and urban populations. For example, because most of Lithuania's population is urban, unstandardized numbers would have yielded significant urban excess in every age category. One way to think about this is as the deviation of the urban and rural age structures from the combined age structure of the entire country.

In 2002, there was a positive urban deviation in Lithuania by the traditional working ages (20-59) and a negative deviation by children and older adults. This age distribution is typical of cities where fertility is relatively low and ageing in place is less prevalent. By 2015, however, this structure had changed. Negative numbers in the two youngest age categories indicate an increase in young urban children. Then,

Regional Statistics, Vol. 7. No.1. 2017: 115-134; DOI: 10.15196/RS07107 
until the mid-20s, there is a positive rural deviation, showing that those who were young children in 2002 did not necessarily immigrate to cities upon reaching young adulthood, at least not immediately after secondary school. There is a small rural peak in the 40- to 50-year-old age group, which had not previously existed, but was large enough to mitigate the positive deviation of rural old people, which became less pronounced.

Figure 3

Standardized differences in age composition between urban and rural areas in Lithuania (\%)

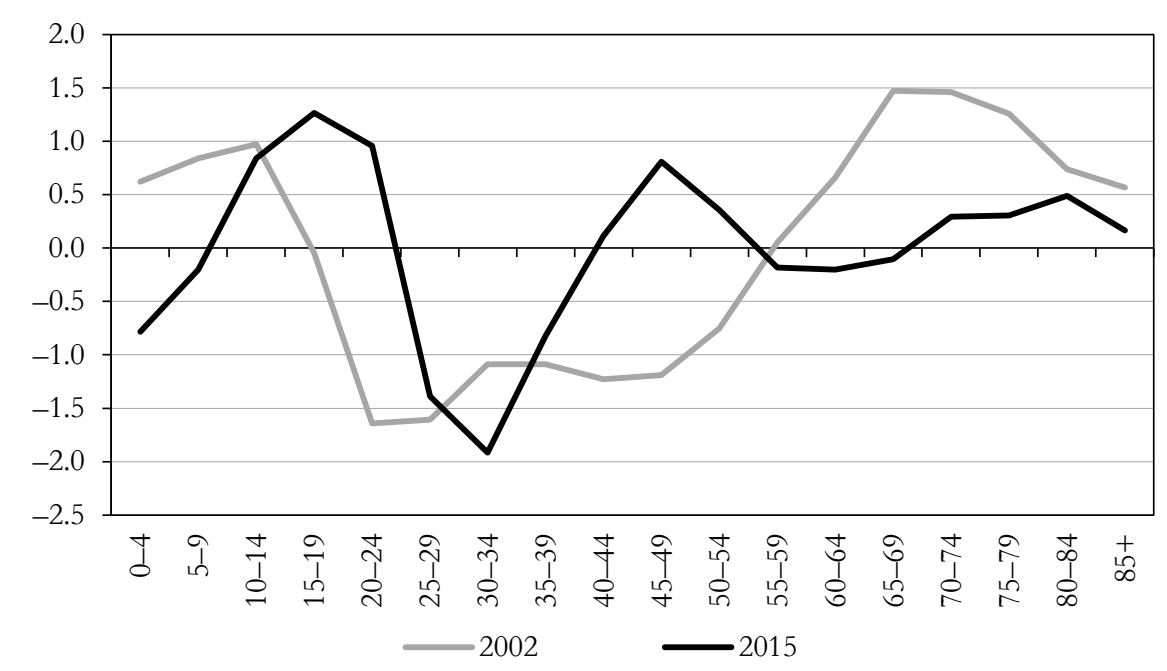

Source: Authors' computations based on OSP and NSI data, respectively.

Numerically, about 20,000 fewer older adults lived in rural Lithuania in 2015 than in 2002. This is a $10 \%$ decline, which is less than the $15 \%$ overall population decline of the country and less than the $17 \%$ decline of the rural areas between 2002 and 2015. Thus, proportionately, because the rural elderly population declined less rapidly than its urban counterpart, the Lithuanian countryside was still ageing, despite the fact that fewer people, including older adults were living there than had been a decade ago.

In Figure 4, the same indicators are shown for Bulgaria. In 2002, Bulgaria already had a distorted age structure, in which urban areas had positive deviations for ages 10 through 55, whereas rural areas had positive deviations for older adults. There was virtually no difference in the younger adult age groups, but a significant rural surplus in the $60+$ segment of the population is observable. This pattern changed little between 2002 and 2015. The notable fact regarding change in this case is the significant, albeit less pronounced, rural positive deviation of older adults. However, we must remember that these differences are compared to changes of the country's

Regional Statistics, Vol. 7. No.1. 2017: 115-134; DOI: 10.15196/RS07107 
overall age composition. Thus, an overall ageing trend coupled with the emigration of young adults (and their families), dynamics that Bulgaria definitely experiences, might generally suppress urban-rural differences in particular age groups.

Figure 4

Standardized differences in age composition between urban and rural areas in Bulgaria (\%)

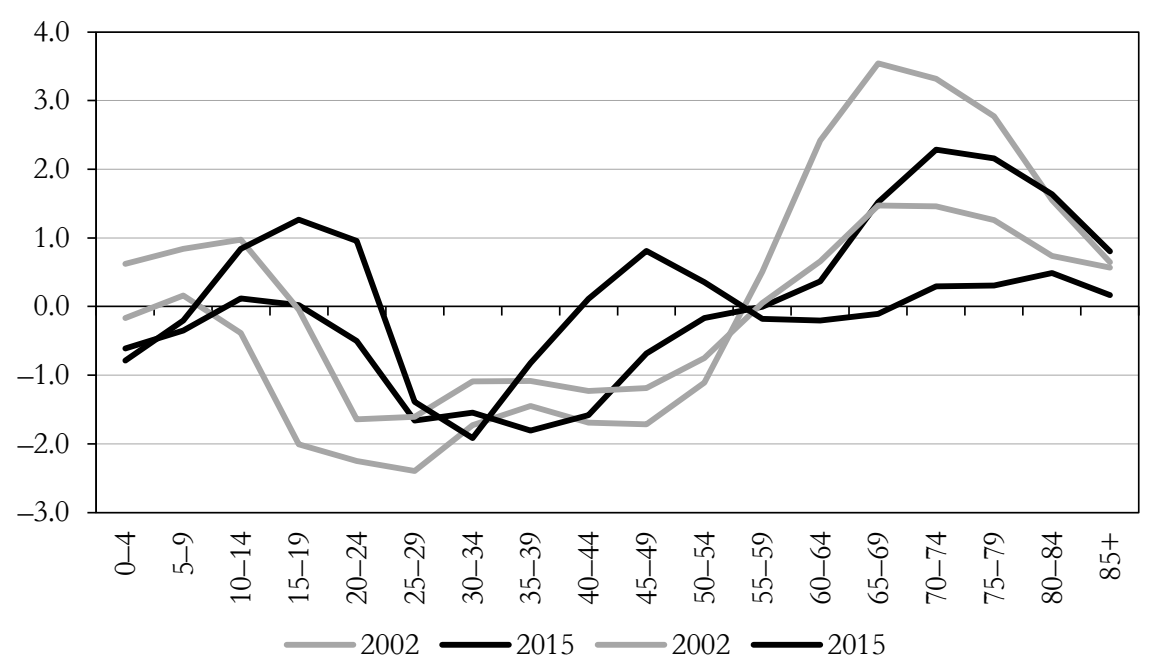

Source: Authors' computations based on OSP and NSI data, respectively.

Bulgaria's overall population decline was 9\% between 2002 and 2015, but its rural area lost 19\% of its population. Similar to Lithuania, the per cent decline in the rural elderly population was smaller, at $15 \%$; thus, the same ageing in place can be observed in Bulgaria as was found for Lithuania. During the same period, Bulgaria lost 90,000 older adults in rural areas, which is another reason for the smaller agespecific bulge in 2015 .

Differences between Lithuania and Bulgaria are more evident when the shapes of their population pyramids are compared (Figure 5). For Lithuania, the wider bars of the upper age categories (rural as well as urban) in 2015 indicate overall population ageing. The relatively large 10-19-year-old age cohort in 2002 had entered its childbearing years by 2015, which is observable in the widening lower bars of the pyramid. Although that is a straightforward cohort effect and not a fundamental change in ageing trends, it gave a long-needed boost to fertility. The most important comparison between Lithuania's urban and rural areas is that this fertility effect also is observed on the rural side of the pyramid, at least for those in their early $20 \mathrm{~s}$. The typical young adult rural dent in the pyramid is not observed until the 25-29 age group.

Regional Statistics, Vol. 7. No.1. 2017: 115-134; DOI: 10.15196/RS07107 
Standardized urban/rural population pyramids for Lithuania and Bulgaria
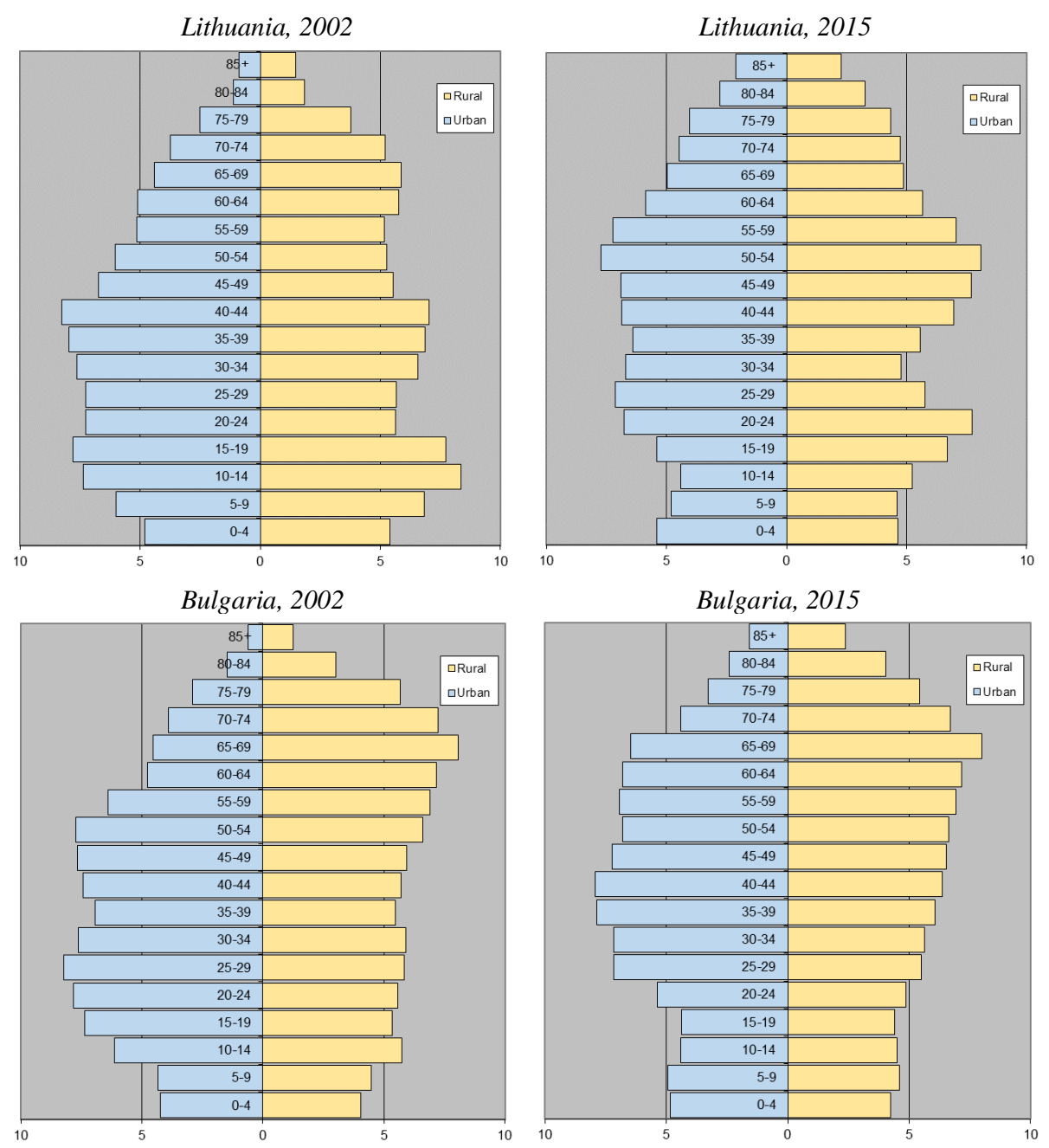

Source: Authors' computations based on OSP and NSI data, respectively.

The Bulgarian story is somewhat different. Rural Bulgaria already had a topheavy age pyramid in 2002 with a deficit in the numbers of people in the workingage cohorts. This was even more pronounced by 2015. Bulgaria also evidenced a cohort effect of young adults entering their childbearing years, but that only occurred in urban places, and, even there, it provided only mild relief. On the other hand, instead of the rural young adult dent, we observe a continuous lengthening of the age bars starting at ages 15-19, which shows the progressive ageing in the countryside.

Regional Statistics, Vol. 7. No.1. 2017: 115-134; DOI: 10.15196/RS07107 
Ageing in Bulgaria's rural areas offers implications somewhat different from its urban ageing for two reasons. First, rural areas have smaller population sizes and lower population densities. Second, and closely related to population size and density, the institutional capacities of most rural places are far more limited in the provision of necessary services for the elderly. In other words, rural areas often have small and shrinking economic bases and revenue streams, limited local revenue, and under-resourced governments and related institutions. This limited capacity in human, organizational, and financial resources is coupled with greater challenges to the availability of affordable services because of low population density, sparse populations, and the resulting low economies of scale and higher per unit costs of services. Geographically small and remote areas typically cannot benefit from economies of scale, even when there is concentration of the target population, which, in our case, are older adults, creating a demand for the services. The rural challenges identified by Glasgow and Berry (2013) of geographic isolation, small populations, relatively few businesses and services, and relatively low financial capacity definitely apply to the rural areas of Eastern Europe. Furthermore, using the example of Hungary, Szilágyi and Gerse (2015) demonstrated the differences in some socioeconomic conditions and demographic trends based on a community's position in the central place hierarchy.

\section{Further integrating the micro-level and macro-level perspectives}

Studies on ageing from a micro-level perspective typically examine individual experiences with a focus on the biological aspects of change. However, it is important to acknowledge that such change always occurs in a community context, and individual experiences are strongly influenced by the characteristics of the places where people live. Rural places are good examples of this interrelationship, and, as pointed out in the previous section, rural areas' unique challenges make a good case for both scholarly inquiry and policy intervention.

It is generally accepted that rural communities have vulnerabilities specific to their unique demographic trends and interrelated development pathways. For example, in the cases of Canada and New Zealand, Joseph and Cloutier-Fisher (2005) used the term 'double jeopardy', arguing that a community is more than the aggregate of its citizens because it has particular conditions that may exacerbate disadvantages. They stated that ageing is a 'situated experience' (Joseph-Cloutier-Fisher 2005:146), particularly for those older adults who are less healthy and mobile over time. For those elders, their 'place', which is their community, neighbourhood, and, perhaps, eventually their homes, becomes an increasingly large part of their experience as they age in place. From an individual perspective, the shrinking geographic horizon of service availability carries with it far greater challenges to service provision for rural communities than for cities. In cities, the lower proportion of elders

Regional Statistics, Vol. 7. No.1. 2017: 115-134; DOI: 10.15196/RS07107 
does not mean numerically fewer of them than in rural areas, which allows economies of scale to emerge on a relatively strong revenue basis. Moreover, urban elders generally have relatively better access to a variety of transportation modes, which potentially alleviates possible social isolation and alienation from services.

Joseph and Cloutier-Fisher (2005) further proposed that, to understand vulnerability (or, arguably, any particular condition), one must look at both the personal experience and the space or place where they occur. This perspective is a crucial component of our proposed framework, and it is consistent with environmental psychologists Lawton and Nahemow's (1973) 'person-environment fit'. A previous application of this perspective was a study on rural ageing in Romania and Bulgaria conducted by Kulcsár and Bradatan (2014). That study added a third layer to the investigation of rural ageing, namely, the overall context of the post-socialist transition, which situated the ageing experience at the community level in the specific context of the transforming Eastern European periphery. These case studies found that the market transition was just one component of the difficulties being faced by rural areas in Eastern Europe. Changing cultural norms about long-term care and family obligations played an equally important part in determining the quality of life of older residents and contributed to a radical change in rural life.

International scholarship provides examples that more positively frame ageing. Rural places with numerous amenities fare quite well, and they successfully transition from places of production to places of consumption (see, for example, SilvaFigueiredo, 2013). Many Eastern European rural areas have actively branded themselves as authentic rural experiences to compete for Western tourists (Hall 2004). Rural retirement migration, often based on rural areas' natural amenities, is a development strategy in the US, Spain, Italy, and other places in Europe. Research has found that older in-migration had strong positive multiplier effects that resounded throughout a community's economy (Stallman et al. 1999); while other studies have shown that destination communities place a high value on the abundant volunteer services provided by older in-migrants (Brown-Glasgow 2008). Of course, these studies assume that older in-migrants will eventually leave to live closer to their children when they experience declining health and/or other negative life course events in later old age (Litwak-Longino 1987). However, it is a risky bet because many in-migrants will age in place; then, their contributions to the community will fall below the costs of maintaining their quality of life and many of those costs will be shouldered by the locality. In addition, the presence of natural amenities is not necessarily sufficient for turning around rural affairs, and infrastructural development, which requires resources and investment before gains can be realized, is necessary to capitalize on those amenities (Brown et al. 2011).

The importance of population ageing at the local level for Eastern Europe can be examined through a coupled micro-macro framework. The micro level addresses existing and potential community capacities to provide a variety of services to older

Regional Statistics, Vol. 7. No.1. 2017: 115-134; DOI: 10.15196/RS07107 
adults and to facilitate their continual social engagement. This situated approach is an enhanced perspective compared to the traditional understanding of micro-level approaches that focus solely on individuals or households. As we argued, an individual's experiences should be understood in the context of the opportunities and constraints of that individual's community. These opportunities and constraints constitute community capacity, which is influenced by the macro-level transitions occurring in Eastern Europe. The question to focus on concerns the type(s) of community forces that shape individual experiences of ageing.

Table 3

Framework for a coupled micro-macro approach

\begin{tabular}{l|l}
\hline \multicolumn{1}{c|}{ Themes at the micro level } & \multicolumn{1}{c}{ Orienting items } \\
\hline Institutions and legacies & $\begin{array}{l}\text { Organization of municipal government and institutions; history } \\
\text { of municipal structures (pre- and post-transition); local } \\
\text { governance; capacity for collaboration and/or grant writing. } \\
\text { Access to hospitals and specialty care; availability of nursing } \\
\text { homes and long term care facilities; financing of health care and } \\
\text { long term care; the most common unmet needs in these areas. } \\
\text { Availability and affordability of public transportation (buses and } \\
\text { trains); mapping the geographic distribution of important } \\
\text { services and transportation linkages; driving as a potential } \\
\text { substitute. }\end{array}$ \\
$\begin{array}{l}\text { Transportation } \\
\text { Businesses, services, and } \\
\text { community assistance } \\
\text { Frilability and affordability of services provided by both } \\
\text { Formal and informal social } \\
\text { relations }\end{array}$ & $\begin{array}{l}\text { community assistance; business transitions and consolidations, } \\
\text { human resources. } \\
\text { Local cultural norms; reciprocal services, volunteerism; } \\
\text { participation in local decision making; family transition; social } \\
\text { isolation and exclusion; intergenerational relations. } \\
\text { Themes at the macro level }\end{array}$ \\
$\begin{array}{l}\text { Institutional structure } \\
\text { and capacity }\end{array}$ & $\begin{array}{l}\text { Political transformation; national institutional structure; social } \\
\text { security and pension systems; demographic dynamics; public } \\
\text { administration systems. } \\
\text { Economic environment } \\
\text { and resources }\end{array}$ \\
$\begin{array}{l}\text { Opportunities for businesses; subsidies and development } \\
\text { options for service provision in remote / underserved areas; } \\
\text { regional economic conditions (particularly since the post- } \\
\text { socialist transition). } \\
\text { Societal attitudes toward aging; meaning of retirement; the } \\
\text { concept of successful aging in a post-socialist context; traditions } \\
\text { of elder care (family vs. institutional). }\end{array}$ \\
\hline
\end{tabular}

From a broad list, we propose five micro-level community capacity themes: (1) institutions and legacies; (2) healthcare and long-term care; (3) transportation; (4) businesses, services, and community assistance; and (5) formal and informal social relations. These micro-level community capacity themes are embedded in a set of macro-level domains specific to Eastern Europe and its transition, with a particular

Regional Statistics, Vol. 7. No.1. 2017: 115-134; DOI: 10.15196/RS07107 
focus on rural areas: (1) institutional structure and capacity, (2) economic environment and resources, and (3) social and community norms. Table 3 shows this framework with a few typical items on each topic.

The micro-level themes address community capacities as they pertain to the everyday lives of older adults as individuals and as community residents. The organization of institutions and services as well as the opportunities for businesses provide the general context in which the services for are planned and delivered. In our experience, two domains, healthcare and transportation, are particularly important to facilitate the well-being of rural older persons. Rural communities tend to struggle with those domains when municipalities have insufficient revenues and private businesses do not fulfil those needs because of limited returns on investment or insufficient subsidies from higher levels of government. These conditions are typical of Eastern European rural communities. On the other hand, formal and informal social relations have a much larger role in the region because of traditional norms and reciprocal relationships in villages (Brown-Kulcsar 2001). These micro-level forces are embedded in the broad context of Eastern European nations' movements on trajectories with respect to political institutions, economies, and social and cultural norms.

\section{Conclusions}

Rural populations in Europe are ageing. By the middle of this century, one-fourth or more of most of them will be 65 years of age or older. We found that Eastern Europe, although somewhat younger than Western Europe, is significantly ageing. In fact, the data we presented indicate that the rate of population ageing in rural Eastern Europe exceeds that of its Western European counterparts. Hence, the extent of population ageing is converging across the European continent. As other scholars have observed, ageing is particularly challenging to rural areas because of their small size, low density-dispersed populations, and relatively modest fiscal capacities (Glasgow-Berry 2013). How will rural communities respond to their older populations? Although continuing population ageing is quite certain for most rural areas, communities' responses to this fundamental demographic change is not easy to predict, and it will undoubtedly vary dramatically across communities, depending on their current resources, historical legacies, and institutional peculiarities.

Although demographic change, which, in this case, is population ageing, influences older adults' wellbeing and the well-being of their communities, demography is not destiny (Brown-Argent 2016). Rather, the impacts of population ageing on a community's organization are mediated by its social structure and institutions, which, in turn, are embedded in a national-level policy environment that constrains and/or facilitates the community's responses to its growing elderly population. Communities that experience relatively similar population changes, such as declining

Regional Statistics, Vol. 7. No.1. 2017: 115-134; DOI: 10.15196/RS07107 
size and an increased share of older persons, could experience distinctly different outcomes, depending on their economic resources, the perceived salience of population-related problems (such as the cost of pensions), the need for elder care housing, and the extents of leaders' willingness to spend political capital on services for older populations. This is particularly important in regions, such as Eastern Europe, where there are distinct differences in resources among countries and between rural and urban areas (Brown et al. 2007).

As Phillipson and Scharf (2005) observed, it is important to examine the ways in which the lives of older people in rural areas are either advantaged or disadvantaged by prevailing socio-political and economic structures at the national and community levels. Some countries consider population ageing a 'social problem', but others are less negative. Ironically, defining ageing as a problem is more likely in countries with strong social welfare systems. In these cases, in which the social contract provides generous support for retirees, growing elderly populations tend to be perceived as a 'care and pensions issue' draining community resources. In contrast, some countries, particularly those that are similar to the US, with relatively weaker social welfare systems, less public responsibility for elder care and support, and strong market economies, do not necessarily consider an ageing population as a drain on the public purse because maintaining elders' standard of living is considered an individual (and/or family) responsibility.

Studies of ageing populations tend to take an exclusively macro-level or exclusively micro-level approach. These studies are important for investigating dynamics, but we suggest that there is an inherent value to examining ageing from a combined micro-macro perspective. Research in the US has found that the individual expectations and experiences of ageing services are strongly influenced by community capacity and social norms that are functions of social organization and governance structures. The study of individual experiences should, if possible, include community and national factors, and research on macro-level indicators of ageing could be more valuable if the residents' actual experiences were included. That approach would comprise individuals' personal experiences, their communities' characteristics, and the national policies and economic frameworks in which ageing occurs.

Finally, it is important to note that the relationship between ageing experiences at the micro level and the constraints and opportunities present at the macro level is not a unidirectional relationship. Demographic processes occur in contexts of structural changes with strong influences on population dynamics that, in turn, create changing demographics (in our case, the age structure) that continuously influence community capacity as well as individual experience. In other words, this causal interrelationship always presents the possibility of downward or upward cycles of socioeconomic change at the local level. Unfortunately, rural communities experience downward cycles much more often than upward ones and can enter a selfreinforcing underdevelopment trajectory relatively easily. This is not a new phe-

Regional Statistics, Vol. 7. No.1. 2017: 115-134; DOI: 10.15196/RS07107 
nomenon to those who follow the discourse on rural development in the studied region, but rural ageing strains community development long before its effects are evident in urban areas or at the national level. Thus, it is important to investigate the interrelationships between micro-level and macro-level factors with respect to ageing communities to proactively address ageing-related challenges wherever and whenever they appear.

\section{REFERENCES}

BACHRACH, C. (2014): Culture and Demography: From Reluctant Bedfellows to Committed Partners Demography 51 (1): 3-25.

Brown, D. L.-SHUCKSMITH, M. (2017f): Reconsidering Territorial Governance to Account for Enhanced Rural-Urban Interdependence in America Annals AAPSS. 672 (1): 282-301

Brown, D. L.-Kulcsar, L. (2001): Household Economic Behavior in Post-Socialist Rural Hungary Rural Sociology 66 (2): 157-180.

Brown, D. L.-Greskovits, B.-Kulcsar, L. J. (2007): Leading Sectors and Leading Regions: Economic Restructuring and Regional Inequality in Hungary Since 1990 International Journal of Urban and Regional Research 31 (3): 522-542.

BROWN, D. L.-BOLENDER, B. C.-KuLCSÁR, L. J.-GLASGOW, N.-SANDERS, S. (2011): Intercounty Variability of Net Migration at Older Ages as a Path-Dependent Process Rural Sociology 76 (1): 44-73.

Brown, D. L.- Eloundou-EnYegue, P. (2016): Age Structure and Development: Beyond Malthus and Beyond Modernization In: Hooks, G.-COHN, S. (eds.) Handbook of Development Sociology University of California Press, Berkeley.

BRown, D. L.-ARGENT, N. (2016): The Impacts of Population Change on Rural Society and Economy In: SHUCKSMITH, M.-Brown, D. L. (eds.) The Routledge International Handbook of Rural Studies pp. 85-96., Routledge, London.

Brown, D. L.-Glasgow, N. (2008): Rural Retirement Migration: Past, Present and Future Springer, Dordrecht.

Brown, D. L.-KulCSAR, L. (2000): Rural Families and Rural Development in Central and Eastern Europe Eastern European Countryside 6: 5-23.

Compton, P. A. (1985): Rising Mortality in Hungary Population Studies 39 (1): 71-86.

Cunningham, S. A. (2009): Causes of Fluctuating Mortality in Romania European Journal of Population 25 (2): 197-214.

Ehrlich, P. (1968): The Population Bomb Ballentine Books, New York.

European Commission (2014): Population Ageing in Europe: Facts, implications and policies European Commission, Brussels.

European Union (2015): Demography Report 2015. Luxembourg.

Gavroliva, N.-Gavrilov, L. (2009): Rapidly Aging Populations: Russia/Eastern Europe In: UhlenBerg, P. (ed.) International Handbook of Population Aging pp. 113131., Springer, Dodrecht.

Glasgow, N.-Berry, E. H. (2013): Rural Aging in 21st Century America Springer, Dodrecht.

Regional Statistics, Vol. 7. No.1. 2017: 115-134; DOI: 10.15196/RS07107 
Goll, M. (2010): Ageing in the European Union: where exactly? Statistics in Focus 26/2010., Eurostat, Luxembourg.

HALL, D. (2004): Rural tourism development in southeastern Europe: transition and the search for sustainability International Journal of Tourism Research 6 (3): 165-176.

Joseph, A. E.-Cloutier-Fisher, D. (2005): Aging in rural communities In: ANDrews, G. J.- Phillips, D. R. (eds.) Aging and Place. Perspectives, policy, practice pp. 133146. Routledge, London.

KInSELLA, K. G.-PHiLliPS, D. R. (2005): Global aging: The challenge of success 60 (1): 1-44.

KULCSÁR, L. J.-BRADATAN, C. (2014): The graying periphery - aging and community development in rural Romania and Bulgaria Europe-Asia Studies 66 (5): 794-810.

Lawton, M. P.-NAhemow, L. (1973): Ecology and the Aging Process In: Eisendorfer, C.-LAwton, M. P. (eds.) Psychology of Adult Development and Aging American Psychological Association, Washington DC.

Litwak, E.-Longino, C. (1989). Migration Patterns Among the Elderly: A Developmental Perspective Gerontologist 27 (3): 266-272.

MesLÉ, F. (2004): Mortality in Central and Eastern Europe: long-term trends and recent upturns Demographic Research Special Collection 2, Article 3 pp. 45-70.

Milbourne, P. (2012): Special Section: Growing Old in Rural Places Journal of Rural Studies 28 (4): 315-658.

PHILLIPSON, T.- SCHARF, T. (2005): Rural and urban perspectives on growing old: developing a new research agenda European Journal of Ageing 2 (2): 67-75.

PoOL, I. (2005): Age-Structural Transitions and Policy: Frameworks In: TulJAPuRKAR, S.Pool, I.- Prachuabmoh, V. (eds.), Population, Resources and Development: Riding the Age Waves pp. 13-40., Springer, Dodrecht.

Silva, L.-Figueiredo, E. (eds.) 2013. Shaping Rural Areas in Europe: Perceptions and Outcomes on the Present and the Future Springer, Dodrecht.

SZILÁGYI, D.-GERSE, J. (2015): Fokról-fokra a települési lépcsőn - Társadalmi-gazdasági különbségek a településhierarchia-szintek között Magyarországon Területi Statisztika 55 (2): 180-198.

StAllman, J.-Deller, S.-Shields, M. (1999): The Economic and Fiswcal Impact of Aging Retirees on a Small Rural Region The Gerontologist 39 (5): 599-610

Thiede, B.-Brown, D. L.-Sanders, S.-Glasgow, N.-Kulcsar, L. J. (2017): A Demographic Deficit? LocaPopulation Aging and Access to Services in Rural America,1990-2010 Rural Sociology 82 (1): 44-74.

Timberlake, M.-Kentor, J. (1983): Economic Dependence, Overurbanization, and Economic Growth: A Study of Less Developed Countries Sociological Quarterly 24 (4): 489-507.

UNiTED NATIONS-DEPARTMENT OF ECONOMIC AND SOCIAL AFFAIRS-POPULATION DiviSION (2015): World Population Prospects: The 2015 Revision, Key Findings and Advance Tables Working Paper No. ESA/P/WP.241., New York.

VAssiLeV, R. (2005): Bulgaria's Demographic Crisis: Underlying Causes and Some ShortTerm Implications Southeast European Politics 6 (1): 14-27.

World BAnK (2007): From Red to Grey. The "Third Transition" of Aging Populations in Eastern Europe and the former Soviet Union World Bank, New York.

Regional Statistics, Vol. 7. No.1. 2017: 115-134; DOI: 10.15196/RS07107 